\title{
Editorial: We need to bring the calves back to the dairy cows
}

\author{
Sigrid Agenäs* \\ Swedish University of Agricultural Sciences, Uppsala, Sweden
}

As a member of the Editorial Board of JDR I have the opportunity to write an Editorial. I want to use this opportunity to raise the possibility of bringing the calves back to the cows in modern dairy production. It would be great if we could review literature on this matter, but there are almost no publications available that deal with effects of keeping cow and calf together instead of the common separation at birth. There has been, and still are, very good reasons for separating calves at birth but there are also good reasons to study alternatives to this practice. There is a growing concern among both farmers and consumers over possible adverse effects on cows and calves from separation. Most of the attention historically, among consumers as well as research, has focused on effects on the orphan calf, but losing the calf may also add to the challenges for the transition cow. However, we do not know anything about the effects on the cow since all cows that are used in dairy research are separated from their calf within the first day or two after parturition. When consumers become more educated their resistance to early separation gets stronger, as was recently highlighted in transatlantic research (Busch et al. 2017). Organic production has a particular challenge since the ideology of organic production and the expectations from consumers include that the food is produced in a natural way and it is very difficult to argue that it is natural for a new-born mammal to be separated from its mother at birth. However, the discussion goes beyond organic production. From my horizon in Sweden, production of animal derived foods is full of contradictions. Sweden has very extensive animal welfare regulations and our farmers work hard within this framework. At the same time they face very strong opposition from parts of the Swedish society with large groups moving to vegetarian and vegan diets, often because they do not agree with management of production animals. In social media, posts that relate to dairy cows or dairy products quickly get comments on perceived problems with modern dairy production and separating mother and young is one of the most common concerns.

In many parts of the world, particularly in arid areas, the dominating dairy management is to share the milk between humans and the animal offspring by allowing the offspring access to its mother during parts of the day. We now see a number of farms around Europe adopting similar management practices but they do it without the support of science and extension. The growing interest from farmers is one argument for doing research on how to integrate the calves into modern dairy production. The possibility of positive effects on sustainability of the dairy sector (in a broad sense) is another. My curiosity as a scientist also finds the idea attractive because research models where cows and calves are kept together will provide a better overall understanding of the biology of lactation. Current research is lacking the positive control of natural lactation and calf rearing and that has probably tainted our conclusions on how things work. Needless to say, there are also potential benefits in terms of consumer trust and the political climate.

I look forward to seeing submissions reporting data on cows and calves that are kept together, and hope to see a comprehensive literature review when the time is right. If we keep the calves away from their mothers there is a real risk that dairy production will go out of business in markets where animal welfare is a priority for the consumers.

Sigrid Agenäs is Professor in management of ruminants with a focus on lactation biology. She has been a member of the Editorial Board since 2015.

\section{Reference}

Busch G, Weary DM, Spiller A \& von Keyserlingk MAG 2017 American and German attitudes towards cow-calf separation on dairy farms. PLOS ONE 12 e0174013 